steak is less usual here. Nevertheless, there does seem to be a case for bringing the "Heimlich maneuver" to the attention of all who could save life by employing it, and in practice that means the general adult population. First-aid teachers and health educators take note.

${ }^{1}$ Heimlich, H J, fournal of the American Medical Association, 1975, 234, 398.

2 Adelstein, A M, unpublished data, 1976.

\section{Violence and television}

A recent article in the fournal of the American Medical Association lamented the standard of television for children there and called for an organised cry of protest from the medical profession about what, in political terms, was described as a "national scandal."

Calculations suggest that the average American child will have viewed some 15000 hours of television by the time he has graduated from high school, as compared with some 11000 hours of formal classroom instruction. He will, it seems, have witnessed some 18000 murders and countless highly detailed incidents of robbery, arson, bombing, forgery, smuggling, beating, and torture-averaging approximately one per minute in the standard television cartoon for children under 10. There is on average six times more violence during one hour of children's television than in an hour of adult television. Furthermore, by the time a child has reached 18 years he will have had some 35000 television commercials directed at him $-25 \%$ of the television industry's profit is said to come from the $7 \%$ of its children's programmes.

There has been a steady flow of research on the effects of television viewing, nearly all of it pointing in the same direction. Two early endeavours ${ }^{2} 3$ were still able to find control groups of children not yet exposed to television, and these firmly established that there is no single answer to the question of how television affects children, but that different children selectively use whatever is available according to their particular needs. While most take television in their stride some lonely and handicapped children become addicted. Subsequent research has been much concerned with the effects of viewing violence. One such study ${ }^{5}$ showed that children aged 5-6 consistently imitate aggressive filmed models. Another study 6 reviewed 146 published papers representing 50 studies and 10000 children and adolescents from every sort of background, all showing that the watching of violence produces increased aggressive behaviour in the young, and confirming the progression from an unsatisfied need, to selective watchfulness and observation, to imitation, and, through practice, to a lasting addition to the repertoire of behaviour.

Despite a very thorough American inquiry ${ }^{7}$ reported in no fewer than six volumes by the Surgeon General's Scientific Advisory Committee, and despite the publication of television codes and guidelines for children's television programmes, American practice is still a source of great concern.

In Britain this concern is not so much about the quality of children's programmes, which are generally considered to be excellent, as about the quality and quantity of the programmes for adults which many children watch. Most would agree that children's television such as Play School, Blue Peter, and Magpie are well adapted to the time of showing and therefore to the available age-sector of viewing children, and that the programmes are positively beneficial. The Walt Disney-type animal cartoons are certainly full of violence, but of such a stylised nature that few parents or pedagogues raise an eyebrow, and even experimental psychologists would probably find the happenings so far removed from reality as to be no stimulus to identification and imitation. Programmes such as the Lone Ranger, Robin Hood, and Dr Who have their quota (somewhat refined, if not respectable) of violence; it may be argued that anyway children need to recapitulate the stages of social evolution and in doing so they may as well have good models before them as bad.

It is certainly proper to be eternally vigilant about children's programmes and about the degree of commercial intrusion therein; if the facts are as stated, we should support the American call for reform. Yet the content of programmes is not our only responsibility. Some disturbed children (and adults) will search for deviant solutions and will sooner or later find them; their need is for recognition of their problem and help in finding an acceptable solution. Children will always (and perhaps even should) watch a proportion of adult programmes; what is important is the response those children see from their parents, and that the parents should be concerned to watch for any distress and to deal with it appropriately. In such ways stress may be advantageous. No degree of programme refinement will absolve, or substitute for, parental responsibility.

\footnotetext{
'Rothenberg, M B, fournal of the American Medical Association, 1975, 234, 1043.

${ }^{2}$ Himmelweit, H T, Oppenheim, H M, and Vince, P, Television and the Child. London, Nuffield Foundation and Oxford University Press, 1958.

${ }^{3}$ Schramm, W, Lyle, J, and Parker, E B, Television in the Lives of our Children. London, Oxford University Press, 1941.

4 Kniveton, B H, and Stephenson, J M, British fournal of Psychiatry, 1973, $122,53$.

5 British Medical.fournal, 1973, 2, 565.

${ }^{6}$ Libert, R M, Neale, J M, and Davidson, E S, The Early Window: Effects of Television on Children and Youth. Oxford, Pergamon Press, 1973.

7 Technical Report to the Surgeon General's Scientific Advisory Committee. Washington, United States Government Printing Office, 1972.
}

\section{Immunosuppressive therapy in SLE-a reappraisal}

For over a decade now cyclophosphamide and azathioprine (and to a lesser extent chlorambucil) have been widely used in the management of systemic lupus erythematosus, particularly in those patients with severe renal lesions. Use of these drugs seemed logical in a disease characterised by such widespread immunological overactivity, and the dramatic improvement in prognosis achieved by similar therapy in another vasculitic disease, Wegener's granulomatosis, ${ }^{1}$ suggested even to the most sceptical that it might have potential benefits in lupus. Unfortunately the widespread clinical experience now accumulated with these drugs in SLE has not been matched by a parallel number of controlled trials.

The major studies to date have been largely confined to patients with renal SLE and in general have suggested that either cyclophosphamide or azathioprine given in combination with prednisone will produce more benefit (in terms of creatinine clearance, urea, and serum complement) than either drug given alone. ${ }^{2-5}$ Azathioprine reduced proteinuria and improved creatinine clearance, cut the number of hospital admissions, and resulted in a steroid-sparing effect averaging $10 \mathrm{mg} /$ day. ${ }^{5}{ }^{6}$ The second of these studies did not, however, show any additive effect with high dose prednisone in treating 
acute exacerbations of SLE. Comparisons of cyclophosphamide, azathioprine, and placebo have also been made in lupus nephritis. ${ }^{7}$ Cyclophosphamide was found to have a more beneficial effect on urine sediment, proteinuria, and serum complement in one study ${ }^{7}$ and produced symptomatic improvement and a fall in DNA antibody titre in the other. ${ }^{8}$

Recently the results of two larger trials using these agents in SLE have been published ${ }^{9} 10$ in which the benefits produced were marginal. Hahn and her colleagues ${ }^{9}$ carried out a prospective randomised trial comparing prednisone $(60 \mathrm{mg}$ per day initially) to prednisone plus azathioprine (3-4 $\mathrm{mg} / \mathrm{kg}$ body weight per day) in 24 patients with life-threatening SLE. During a mean follow-up period of 18-24 months there were no significant differences in outcome as assessed by the number of deaths, renal and extrarenal manifestations, serum complement levels, and DNA antibodies. There was no convincing evidence of a steroid-sparing effect of azathioprine. In the second study, cyclophosphamide or azathioprine was added to low-dose corticosteroid therapy in 38 patients with diffuse lupus glomerulonephritis. The cytotoxic agents added only marginally to the control of the disease, though it was noted that no SLE-related death, renal or otherwise, occurred among the 12 patients treated with cyclophosphamide. ${ }^{10}$

These important studies throw doubt on the value of immunosuppressive drugs in SLE, but it might be said that the patients were at the severe end of the disease spectrum. In most patients SLE may be a mild disease with a reasonable prognosis, ${ }^{11}$ and it is among these patients that any potential therapeutic effect of immunosuppressive agents requires critical analysis. The long-term risk of malignancy, especially in a disease in which immunodeficiency may play an aetiological part, ${ }^{12}$ must be high, and the case for therapeutic conservatism is strong. When nephritis is established powerful alternatives to corticosteroids are still required; unfortunately the case for immunosuppressives, on present evidence, remains unproved.

${ }^{1}$ Reza, M J, et al, Arthritis and Rheumatism, 1975, 18, 501.

2 Steinberg, A D, et al, Annals of Internal Medicine, 1971, 75, 165.

${ }^{3}$ Schur, P H, and Sandson, J, New England fournal of Medicine, 1968, 278, 533.

4 Cade, R, et al, Nephron, 1973, 10, 37.

5 Sztejnbok, M, et al, Arthritis and Rheumatism, 1971, 14, 639.

${ }^{6}$ Ginzler, E, et al, Arthritis and Rheumatism, 1975, 18, 27.

' Steinberg, A D, et al, Arthritis and Rheumatism, 1972, 15, 456.

${ }^{8}$ Steinberg, A D, and Decker, J L, Arthritis and Rheumatism, 1974, 17, 923.

${ }^{9} \mathrm{Hahn}, \mathrm{B}$ H, Kantor, O S, and Osterland, C K, Annals of Internal Medicine, 1975, 83, 597.

${ }_{10}$ Decker, J L, et al, Annals of Internal Medicine, 1975, 83, 606.

11 Fessel, W J, Archives of Internal Medicine, 1974, 134, 1027.

${ }^{12}$ Hughes, G R V, and Lachmann, $\mathrm{P}$ J, in Clinical Aspects of Immunology, ed P G H Gell, R R A Coombs, and P J Lachmann, 3rd edn, p 1117. Oxford, Blackwell, 1975.

\section{Nostalgia: a vanished disease}

\author{
Name me no names for my disease, \\ With uninforming breath; \\ I tell you I am none of these, \\ But homesick unto death.
}

Witter Bynner 1881-1968

In other countries it was called mal du pays, Heimweh, malatia del pais, and the disease had already acquired a scientific name, nostalgia-a term coined by Johannes Hofer in a work published in Basle in 1678. For more than two centuries the disease appeared in medical textbooks and was the subject of many medical papers. The great Karl Jaspers, for example, wrote a paper ${ }^{1}$ in 1910 giving 86 references to it. Since then it has almost disappeared as a clinical entity, but interest in the subject may revive as a result of Professor George Rosen's recent erudite historical review, ${ }^{2}$ which ends-too early, one feels-with the American Civil War.

In the main the symptoms were those of what today we would mundanely call an anxiety state or a reactive depression; but some of them-stupor, fever, night sweats, delirium, hallucinations-point with hindsight to other diagnoses. So, too, does the criminal behaviour, including arson, shown by the young foreign servant girls described by Jaspers ${ }^{1}$ and the fatal outcome mentioned by various authors.

Bizarre theories of the cause of the disease were suggested. The body fluids were said to be "vitiated"; the Swiss were thought to be specially at risk (hence another name, Schweizerkrankheit) because they missed the thin atmosphere of their mountains; the sound of the bagpipes provoked the disease in Scots soldiers serving as mercenaries abroad. But both early and late its prime cause was always recognised ${ }^{3}$ as "a strong, emotionally charged desire to return home"; and the cure was to send the patient home. Naturally, soldiers and sailors were especially prone to it.

Vanished diseases are not very common. Chlorosis, encephalitis lethargica, and very soon smallpox are three of the few examples. Nostalgia as a clinical diagnosis has all but gone from the scene this century in spite of two great wars and their aftermath, "a swirling tide of human movement." It may have disappeared from medical literature, and in particular from the titles of military medicine of the last six years, but it continues as an influence in three guises: as a nearuniversal experience in migrants whether forced (refugees) or voluntary (immigrants, migrant workers); it is one of the many factors probably responsible for the higher incidence of neurosis in migrants than in native populations (" I cannot live in this country, it is affecting my soul"); and it is possibly a factor causing psychotic illness to be commoner in them too.

There is, indeed, abundant evidence that psychoses, or at least some types of psychosis, particularly schizophrenia, are commoner in immigrants. This evidence dates from the classic paper of Ødergård 6 on Norwegian immigrants to Minnesota compared with both native Americans in Minnesota and Norwegians in Norway. Since then this finding has been repeatedly observed: for example, in migrants from other States into New York State $;^{7}$ Europeans into Australia $;^{8}$ immigrants into Birmingham $;{ }^{9}$ immigrants into Camberwell $;{ }^{10}$ the Irish into Camberwell ${ }^{11}$ migrant workers into Yugoslavia ; ${ }^{12}$ and the West Indians in England have a higher incidence than their compatriots at home..$^{13}$

There is still controversy about the reasons. Are emigrants self-selected by restlessness, instability, lack of success in their native lands, prepsychosis, or even, in a small proportion, psychotic symptoms before they move $\mathrm{e}^{6-814-16}$-the drift theory? Are immigrants at risk of psychotic breakdown because of the stress, including nostalgia, they encounter in their adopted country, so-called reactive psychosis? Or are the figures for migrants inflated only because, as they often live alone, it is more difficult for them when ill to stay out of hospital ? ${ }^{7}$ Indeed, it is not entirely clear whether, if first admission figures are standardised for age, much of the difference in admission rates does not melt away.

With the neuroses there is a closer approach to unanimity. 